\title{
Autoconceito global em estudantes do ensino superior: um estudo comparativo entre iniciantes e finalistas
}

Global Self-concept in higher education students: a comparative study between beginners and finalists

Autoconcepto global en estudiantes universitarios: un estudio comparativo entre principiantes y finalistas

Rita Manuela de Almeida Barros

J. António Moreira*

\section{Resumo}

Este estudo centra-se nos processos de mudança do autoconceito no período designado por pós-adolescência e traduz-se num estudo comparativo entre os níveis de autoconceito global de estudantes do ensino superior, iniciantes e finalistas. Recorrendo a uma metodologia de cariz quantitativo, a nossa amostra foi constituída por 552 sujeitos. Para a avaliação do nível de autoconceito global, valemo-nos da adaptação do Self Description Questionnaire III realizada por Faria e Fontaine (1992) a estudantes universitários portugueses. Concluímos que não existem diferenças significativas entre os dois grupos de estudantes. Esses resultados podem ser compreendidos com base nas experiências e ansiedades vivenciadas pelos estudantes do ensino superior, quer no processo de adaptação ao contexto acadêmico, no caso dos que estão a iniciar a formação, quer na antecipação de reais dificuldades de inserção no mercado de trabalho, no caso dos finalistas.

Palavras-chave: Autoconceito global. Ensino superior. Pós-adolescência.

\begin{abstract}
The present study is centered in the changing processes of self-concept in the period assigned as following-teenage years and is expressed in a comparative study of global self-concept levels, between beginners and finalists higher education students. Based on a quantitative methodology, our sample was composed by 552 individuals. To evaluate the global

\footnotetext{
Doutora em Ciências da Educação pela Universidade de Santiago de Compostela; mestra e licenciada em Psicologia pela Universidade do Porto; professora adjunta na Escola Superior de Educação Jean Piaget; colaboradora da Unidade de Investigação e Formação em Adultos e Idosos (Unifai) do Instituto de Ciências Biomédicas Abel Salazar - Universidade do Porto. E-mail: rbarros@gaia.ipiaget.org.

** Doutor em Ciências da Educação pela Universidade de Coimbra, professor auxiliar no Departamento de Educação e Ensino a Distância da Universidade Aberta. Endereço: Rua do Amial, no 752, 4200-055, Porto, Portugal. E-mail: jmoreira@uab. pt.
} 
self-concept level, we used the Self Description Questionnaire III, adapted by Faria and Fontaine (1992) with Portuguese university students. We conclude that there doesn't exist significant differences between the two groups of students. These results can be understood from the experiences and anxieties lived by higher education students, both in the adaptation process to the academic context, in the case of beginners, or in anticipation of real difficulties in labor market integration, in the finalist's case.

Keywords: Global self-concept. Higher education. Post adolescence.

\section{Resumen}

El presente estudio se centra en los procesos de cambio del autoconcepto en el período designado como post-adolescencia y que se traduce en un estudio comparativo entre los niveles del autoconcepto global de estudiantes universitarios principiantes y finalistas. Basándose en una metodología cuantitativa, nuestra muestra estuvo compuesta por 552 individuos. Para evaluar el nivel de autoconcepto global se usó una adaptación del Self Description Questionnaire III realizada por Faria y Fontaine (1992) a estudiantes universitarios portugueses. Se puede concluir que no existen diferencias significativas entre los dos grupos de estudiantes. Estos resultados pueden ser entendidos a partir de las experiencias y ansiedades vividas por los estudiantes universitarios, tanto en el proceso de adaptación y contexto acadêmico, en el caso de los principiantes, como en la anticipación a las dificultades reales que van a encontrar en el momento de su insercción al mercado, en el caso de los finalistas.

Palabras clave: Autoconcepto global. Enseñanzas universitarias. Postadolescencia.

\section{Introdução}

transição para o ensino superior implica um alargado leque de 4 transformaçôes na vida do jovem, associadas às exigências sociais de maior Lautonomia e independência pessoal. Essas exigências proporcionam um conjunto de experiências desafiantes, mas potencialmente estressantes, que implicam o desenvolvimento de novas relações interpessoais e a adaptação a novos contextos (Dias \& Fontaine, 2001; Santos \& Almeida, 2001). Uma adequada adaptação exige que o estudante reconceitualize as suas experiências, faça novas aquisições e reestruturações pessoais, mesmo que 
isso implique uma fase inicial de desorganização e de baixa autoconfiança. A adaptação acadêmica implica uma maior responsabilização pelos próprios atos, uma maior capacidade para lidar com a mudança, para gerir o tempo, para lidar adequadamente com situaçôes de estresse e para elaborar projetos de planos futuros. Assim, enquanto alguns estudantes encaram o ingresso no ensino superior como uma oportunidade de desenvolvimento pessoal, refletindo níveis moderados de estresse, outros vivenciam esse processo como um momento de crise (Beyers \& Goossens, 2003).

Por outro lado, os estudantes que se encontram na reta final da sua formação superior e prestes a integrar o mercado de trabalho também se deparam com desafios importantes que implicam a capacidade de autoexploração e o desejo de alcançar, preservar e sublinhar a sua autonomia e independência pessoal. As competências adquiridas na escola terão de ser aplicadas no contexto laboral, e o elevado autoconceito se associa a profissões mais diferenciadas, que envolvem um maior grau de autonomia, de capacidade de tomada de decisão e de resolução de problemas. Essa transição também se poderá afigurar como elemento indutor de estresse, dadas as incertezas e ambiguidades, no que diz respeito ao primeiro emprego, e considerando os atuais desafios da nova organização do trabalho e do mundo atual.

Assim, na passagem da adolescência tardia para a vida adulta, surgem transformações que condicionam o autoconceito, designadamente as mudanças ao nível da identidade de papel e uma expansão da identidade existencial.

No contexto português, o estudo transversal realizado por Seco (1993), dedicado ao estudo da estabilidade versus mudança do autoconceito escolar em estudantes do ensino superior, não detectou diferenças associadas ao ano de frequência do curso e à idade. Conclui-se que o autoconceito parece ser um bom preditor do sucesso escolar, pelo que se justifica uma atenção mais rigorosa na análise das variáveis pessoais e afetivas do estudante do ensino superior.

As instituições de ensino superior, para além da formação científica e técnica, têm vindo a evidenciar, justamente, uma maior preocupação com as componentes humanas e relacionais e com as dimensões socioafetivas, salientando o papel de variáveis que ultrapassam o domínio cognitivo, por exemplo, o autoconceito, no desempenho acadêmico e profissional (Simões \& Serra, 1987; Faria \& Fontaine, 1990; Veiga \& Moura, 1993; Janeiro \& Marques, 1999). O estudo de Stocker e Faria (2009) sobre o autoconceito e a adaptação ao ensino superior é outro exemplo claro dessa preocupação. 
$\mathrm{Na}$ realidade, essa tendência é concomitante com um maior investimento na exploração dos conceitos que anexam o prefixo auto, designadamente no domínio da ciência psicológica. Não obstante, autores, como Harter (1983), defendem que as questóes que se prendem com a estabilidade/mudança do autoconceito carecem de mais investigação, pois são escassos os estudos, sobretudo os de caráter longitudinal, que se centram na análise do self em períodos de transição do desenvolvimento ou na relevância relativa das diferentes dimensões do autoconceito, em diferentes timings do ciclo vital e em diversos contextos de mudança ou de estabilidade.

Por todos esses aspectos, interessa às instituições de ensino superior conhecer de que forma se altera o autoconceito dos jovens, desde que iniciam a sua formação até ao momento que estão prestes a ingressar no mercado de trabalho, no sentido de apurarem práticas pedagógicas mais consistentes $\mathrm{e}$ direcionadas. A importância do autoconceito em contexto escolar tem vindo a ser alvo de atenção na literatura científica subordinada ao tema (Faria, 2003; Simões, 2001), designadamente na sua relação com a promoção de competências desejáveis ao exercício da futura atividade profissional (e.g., Melo, 2005).

Apesar da diversidade e heterogeidade inerente à definição do constructo, o autoconceito é, de forma global, entendido como a percepção que o sujeito tem de si mesmo (Shavelson \& Bolus, 1982; Vaz Serra, 1986), tendo como sustentação um rationale teórico de inspiração cognitivo-construtivista, segundo o qual o processo de autoconstrução realiza-se por meio da forma como os indivíduos representam ou estruturam cognitivamente o mundo (Marsh \& Hattie, 1996). Faria e Fontaine (1990), definem-no da mesma forma, em termos globais e, em termos específicos, como o conjunto de atitudes, sentimentos e conhecimentos acerca das capacidades, competências, aparência e aceitabilidade social próprias. Gecas (1982), citado por Valente (2002), define o autoconceito como o conceito que o indivíduo faz de si próprio como um ser físico, social e espiritual ou moral.

Atualmente, a maior parte da investigação aceita os contributos dos modelos estruturais do autoconceito, modelos que evocam o caráter desenvolvimental. Nesse referencial, o autoconceito é composto por múltiplas facetas ou dimensóes organizadas de forma hierárquica. Com base nas experiências de vida, o sujeito retira informações acerca de si próprio, estruturando-as em categorias de síntese mais simples, por forma a organizar toda a experiência, conferindo-lhe sentido. Essas experiências organizam-se em diferentes áreas que representam facetas específicas do autoconceito, sendo a sua relevância relativa condicionada pela fase do ciclo vital no qual o indivíduo se encontra. 
De qualquer das formas, todas estas áreas estão vinculadas à dimensão geral do autoconceito e organizam-se hierarquicamente, sabendo-se que as áreas mais valorizadas pelo sujeito terão um maior impacto na percepção que tem de si. $\mathrm{Na}$ base dessa hierarquia, encontram-se as situações específicas com as quais o indivíduo se confronta que, apesar de mais instáveis, isto é, potencialmente mais inconsistentes e dissonantes em relação ao autoconceito geral, podem não provocar, de forma mais direta e imediata, mudanças na percepção global que o sujeito tem de si, tendencialmente mais estável (Marsh \& Hattie, 1996). No entanto, essa percepção global condiciona a forma como os indivíduos se adaptam às transições de vida, permitindo "prever a realização profissional, inserção social e o bem-estar global dos indivíduos" (Lima Santos, Rurato \& Faria, 2000, p. 207). A transição da escola para o trabalho parece influenciar as dimensóes avaliativas do autoconceito. As competências adquiridas na escola terão de ser aplicadas no contexto laboral, e o elevado autoconceito está associado a profissões mais diferenciadas, que envolvem um maior grau de autonomia, de capacidade de tomada de decisão e de resolução de problemas.

Os estudos que se centram na relação entre o autoconceito e a idade apontam para uma estabilidade temporal relativa (Gecas \& Mortimer, 1987). Dias e Fontaine (2001) não registaram diferenças no autoconceito global entre estudantes do ensino superior iniciantes e finalistas. Torna-se aqui importante a recomendação de investigadores como Marsh (1989), em relação à dificuldade de generalização das investigaçôes realizadas. Os estudos como os de Long e colaboradores (1986) ou de Protinsky e Wilkerson (1986), citados por Valente (2002), defendem que os níveis de autoconceito aumentam com a idade.

No entanto, opiniōes opostas são veiculadas nos estudos de Wylie (1979, citado por Marsh, Barnes, Cairns \& Tidman, 1984), sustentadas na ideia de que, com a idade, aumenta o nível de aspiraçóes do sujeito e o seu contato com a realidade, o que gera um nível mais elevado de frustração, com todas as implicações em termos do seu autoconceito. Segundo eles, não é possível falar de evidências contundentes do efeito da idade no autoconceito global, entre os 6 e os 50 anos.

Os resultados de estudos realizados em Portugal, como os Dias e Fontaine (2001) e Valente (2002) não registaram diferenças no autoconceito por causa da idade dos sujeitos, estudantes do ensino superior. Podemos assim falar numa estabilidade relativa ou numa mutabilidade pouco expressiva.

No que diz respeito às diferenças de autoconceito entre sexos, os estudos (e.g., Marsh, 1994) mostram que, embora não se registrem diferenças de gênero no autoconceito global, existem diferenças que favorecem o sexo feminino nalgumas áreas e diferenças que favorecem o sexo masculino noutras. 
O nível socioeconômico e sociocultural tem sido alvo de menor interesse por grande parte dos estudos dedicados à análise do autoconceito (e.g., Crain, 1996; Marsh, 1989), pelo que nos pareceu importante incluir essas variáveis na nossa pesquisa. Estudos como os de Valente (2002) mostram que "pais com habilitaçóes mais elevadas estarão mais aptos a ajudarem os filhos na construção de um bom autoconceito global” (p. 159), mas revelam a existência de resultados contraditórios nessa área, pois, embora grande parte dos estudos aponte para níveis superiores de autoconceito nas classes social e culturalmente mais elevadas, outros há que não evidenciam tais diferenças.

Atualmente, a investigação relativa ao autoconceito orienta-se em diferentes sentidos. Alguns estudos centram-se no apuramento de instrumentos de avaliação do constructo e na clarificação da terminologia usada, enquanto outros analisam o impacto dos fatores sociais e culturais no autoconceito, a sua natureza hierárquica e os seus efeitos nos aspectos vivenciais dos sujeitos (Marsh \& Hattie, 1996). A investigação que desenvolvemos enquadra-se nessa segunda orientação e toma o conceito de si próprio como um organizador e regulador da ação, que poderá facilitar a atribuição de significado às experiências passadas e incentivar os projetos futuros. Por outro lado, embora seja vasta a literatura que se dedica ao processo de desenvolvimento do autoconceito (Hattie, 1992), a idade adulta é aquela que tem merecido menor atenção, e a grande maioria dos estudos centra-se na infância e adolescência, pelo que esta investigação pretende contrariar essa tendência. Saliente-se ainda que optamos por estudar a dimensão global do autoconceito, porque pretendemos proceder a uma análise mais macroscópica e, como tal, menos diferenciada, do seu desenvolvimento. Pressupomos que outras facetas, que não apenas a acadêmica, têm cada vez maior relevância na adaptação, quer ao contexto de ensino superior, quer ao contexto de trabalho, pese embora a estreita relação entre o autoconceito acadêmico e o rendimento acadêmico (Byrne, 1996).

\section{Objetivos}

O objetivo central que definimos traduz-se na identificação de possíveis mudanças nos níveis de autoconceito global entre os estudantes que se encontram a iniciar a sua formação superior e os estudantes que se encontram prestes a ingressar no mercado de trabalho. Os elevados ou moderados níveis de estabilidade no autoconceito não excluem a ideia da influência das mudanças sociais no self, sobretudo daquelas que se associam aos papéis desempenhados. Assim, pretendemos, fundamentalmente, comparar o autoconceito global entre alunos do ensino superior, no início e final da sua formação, atendendo em simultâneo às variáveis idade, sexo, nível socioeconômico e nível sociocultural. 


\section{Metodologia}

Apresentamos um estudo comparativo de natureza quantitativa, não experimental, com caráter transversal, inserindo-se num referencial teórico de inspiração cognitivo-construtivista e de cariz nitidamente desenvolvimental, ao privilegiar a percepção subjetiva dos jovens sobre o seu próprio desenvolvimento.

Os estudos comparativos centrados no autoconceito dos estudantes em diferentes fases da formação superior afiguram-se pertinentes para o conhecimento das suas eventuais flutuações e, consequente, para a facilitação dos processos de preparação nas transições acadêmicas.

\section{Amostra}

O universo em estudo foi constituído por estudantes do ensino superior, a frequentar o Campus Acadêmico de Vila Nova de Gaia, ao nível da formação inicial, num total de 2427 estudantes, distribuídos pela Escola Superior de Educação (2 159) e pela Escola Superior de Saúde (268) do Instituto Piaget. A amostra foi recolhida junto dos estudantes que se encontravam inscritos nos $1^{\circ}$ e $4^{\mathrm{o}}$ anos dos cursos de Educação e no $1^{\mathrm{o}}$ ano dos cursos de Saúde. ${ }^{1}$ No primeiro caso falamos de cursos de Educação em funcionamento na Escola Superior de Educação, selecionados aleatoriamente, nomeadamente os cursos de Educação de Infância e de Professores do Ensino Básico do $1^{\circ}$ e $2^{\circ}$ Ciclos. Os cursos da Escola Superior de Saúde, designadamente os cursos de Enfermagem, Análises Clínicas e Dietética, foram selecionados da mesma forma, num conjunto de seis que se encontravam em funcionamento. Recorremos a eles por forma a equilibrar o número de estudantes no início e no final da formação superior.

Por se tratar de uma amostra por conveniência, selecionada em função da acessibilidade, não podemos tomá-la como representativa da população portuguesa a frequentar o ensino superior, pelo que os resultados não são passíveis de generalizações. A nossa amostra ficou, assim, constituída por 552 sujeitos.

A idade dos sujeitos situou-se entre os 17 e os 54 anos, sendo a média de 22,87 e o desvio padrão de 3,859.

Em relação à variável sexo, $438(79,3 \%)$ pertencem ao sexo feminino, e 114 $(20,7 \%)$ ao sexo masculino, o que, aliás, traduz uma tendência expressa, já há alguns anos, no que concerne à população que frequenta o ensino superior

\footnotetext{
1 A Escola Superior de Saúde entrou em funcionamento no ano letivo em que se efetuou a recolha de dados, pelo que a amostragem apenas pode considerar os alunos que frequentavam o seu primeiro ano de formação.
} 
português. Duzentos e cinquenta dos estudantes da amostra $(45,3 \%)$ frequentam o $1^{\circ}$ ano do ensino superior, e 302 alunos frequentam o $4^{\circ}$ ano $(54,7 \%)$.

A operacionalização da variável nível socioeconômico teve por base a categorização da atividade profissional desenvolvidas pelos pais, que concretizamos recorrendo à Classificação das Profissões de 1994, proposta pelo Instituto Nacional de Estatística de Portugal (INE). Os resultados dessa categorização foram posteriormente aglutinados nos três níveis socioeconômicos definidos (baixo, médio e alto). A maior parte da amostra (40,2\%) situa-se num nível baixo, $21,75 \%$ correspondem a um nível elevado, e 33,7\% dos sujeitos pertencem ao nível médio.

Definimos três níveis na operacionalização na variável nível sociocultural (baixo, médio e alto), com base nas habilitações acadêmicas dos pais. ${ }^{2}$

Verificamos que mais de metade dos sujeitos que pertencem à nossa amostra se situam num nível sociocultural baixo (52,9\%), 29,2\% situam-se num nível médio, e apenas $15 \%$ pertencem ao nível elevado.

\section{Instrumento}

Relativamente ao instrumento de avaliação, optamos por recorrer ao SDQ III (Self Description Questionnaire) dirigido a jovens adultos e dividido em 13 dimensões do autoconceito (domínio acadêmico, área verbal, área da Matemática, aparência física, competência física, relação com os pais, relações com os pares do mesmo sexo, relações com os pares do sexo oposto, estabilidade emocional, honestidade/fiabilidade, resolução de problemas, valores espirituais/religiāo, global), organizadas em três grandes facetas: autoconceito acadêmico, autoconceito não acadêmico e autoconceito global. Para o nosso estudo, utilizamos precisamente a subescala de autoconceito global, relativamente unidimensional e sem conteúdo específico, composta por itens que permitem inferir o valor próprio e a autoeficácia, aplicáveis a muitas áreas específicas (Marsh \& Hattie, 1996). A subescala de autoconceito global é composta por 12 itens $(3,16,29,42,55,68,81,94,107,120,131$, 135), e as suas pontuaçôes variam entre um mínimo de 12 e um máximo de 96. Cerca de metade dos itens são apresentados em ordem inversa $(3,29,55$, $68,94,131)$, indo ao encontro da recomendação de Likert, segundo a qual as escalas devem ser equilibradas, com aproximadamente o mesmo número

\footnotetext{
Ao nível baixo correspondem os sujeitos que não têm escolaridade ou que frequentaram o $1^{\circ} \mathrm{e}(\mathrm{ou})$ o $2^{\circ}$ ciclo(s) do ensino básico. Ao nível médio correspondem os sujeitos que frequentaram o $3^{\circ}$ ciclo do ensino básico ou o ensino secundário. Por último, os sujeitos que frequentaram o ensino superior foram categorizados no nível sociocultural elevado. Uma vez que na nossa pesquisa reunimos informação acerca dos dois progenitores, optamos, nesta nossa classificação, por considerar sempre o progenitor que apresentasse o nível sociocultural mais elevado, operacionalizando, dessa forma, a variável. Quando a informação relativamente a um deles foi omissa, procedemos da mesma forma.
} 
de itens positivos e negativos, para evitar respostas estereotipadas (Morales Vallejo, 2006). As respostas recaem numa escala do tipo Likert de 8 pontos, desde 1 (discordo totalmente) até 8 (concordo totalmente).

Para além das qualidades psicométricas evidenciadas por esse instrumento de avaliação e da sua referência no campo internacional como um dos mais completos, a opção pelo seu uso justifica-se, também, pelo fato de já ter sido adaptado à população portuguesa por Faria e Fontaine (1992). Nesse processo, o instrumento foi inicialmente sujeito a uma reflexão falada e, posteriormente, foi submetido a uma análise da sua consistência interna, por meio do coeficiente de alpha de Cronbach e da análise factorial. Quanto ao coeficiente alpha, os valores situaram-se entre os 0,80 e os 0,94 , à exceção da dimensão honestidade/fiabilidade, com 0,74 e a dimensão relativa à resolução de problemas, com 0,75 . "[...] a consistência interna das escalas no contexto português parece ter sido confirmada” (Faria \& Fontaine, 1992, p. 44). No que diz respeito à análise factorial,

Apesar das escalas do SDQ III não se apresentarem tão claramente distintas na amostra portuguesa como na amostra australiana, constatamos que o agrupamento de certos itens de escalas diferentes tem sentido na fase de desenvolvimento que o jovem adulto atravessa (Faria \& Fontaine, 1992, p. 47).

A avaliar pelas qualidades psicométricas satisfatórias que apresenta, parecenos de todo legitimada a sua utilização. Acresce ainda o fato de que este é um instrumento que se tem revelado útil para a investigação, planejamento e avaliação da intervenção no âmbito do autoconceito em adolescentes e jovens adultos do contexto escolar português (Azevedo \& Faria, 2003; Faria \& Azevedo, 2004).

A recolha de dados realizou-se durante o período letivo cedido por professores que se disponibilizaram a colaborar. Aos alunos foram garantidos o anonimato e a confidencialidade individual dos resultados.

\section{Procedimento e análise estatística}

Para a análise estatística dos dados recolhidos, recorremos ao SPSS (Statistical Package for the Social Sciences). Os procedimentos estatísticos adotados passaram pela estatística descritiva e inferencial. Considerando o tamanho da amostra e o fato de os dados não escaparem à distribuição normal, optamos pela estatística paramétrica. Utilizamos a média como medida de tendência central e recorremos também ao desvio padrão como medida de dispersão. Usamos o $t$-test para amostras independentes e a análise 
de variância multifactorial (Anova). O nível de significância foi definido para um intervalo de $95 \%$ de confiança.

A validade externa dos resultados é limitada aos estudantes do referido estabelecimento de ensino ou, quando muito, aos estudantes que frequentam instituições de formação de professores com perfil semelhante ao estudado.

A análise comparativa estabeleceu-se entre o início e o final da formação superior, considerando ainda as variáveis sociodemográficas em apreço.

\section{Resultados}

Relativamente à comparação entre as variáveis autoconceito global e ano de frequência do ensino superior, verificamos, com base no $t$-test para amostras independentes, que não existe uma diferença significativa entre os dois anos de formação considerados, $\mathrm{t}(552)=-2,17, \mathrm{p}=0,93$.

Relativamente à questão do gênero, mais uma vez, verificamos a inexistência de diferenças significativas entre os níveis de autoconceito apresentados pelos sujeitos do sexo masculino e do sexo feminino, $\mathrm{t}(552)=-1,86, \mathrm{p}=0,71$. Verificamos, ainda, que a ausência de diferenças entre homens e mulheres se repete quer no início $(\mathrm{t}(250)=-0,21, \mathrm{p}=0,62)$, quer no final da formação superior $(\mathrm{t}(302)=-1,25, \mathrm{p}=0,27)$. Ao analisarmos apenas os indivíduos do sexo masculino $(\mathrm{N}=114)$ quanto ao nível de autoconceito, verificamos que não se registam diferenças estatisticamente significativas nas médias entre o $1^{\circ}$ $(M=70,83)$ e o $4^{\circ}$ ano $(M=73,66)$ de formação, $\left.t(114)=-2,83, p=0,28\right)$. E se considerarmos apenas os sujeitos do sexo feminino $(\mathrm{N}=438)$, verificamos que também não se registram diferenças estatisticamente significativas entre o $1^{\circ}(\mathrm{M}=73,02)$ e o $4^{\circ}$ ano $(\mathrm{M}=76,24)$ de formação quanto às médias de autoconceito global, $\mathrm{t}(438)=-3,22, \mathrm{p}=0,42)$.

No que diz respeito à comparação das variáveis autoconceito global e nível socioeconômico, através de uma Anova, verificamos que não existem diferenças, $\mathrm{F}=0,63, \mathrm{p}=0,53$. As Anovas efetuadas por ano de frequência permitem, também, verificar que não existem diferenças nos níveis de autoconceito global de acordo com o nível socioeconômico, quer nos estudantes do $1^{\mathrm{o}}$ ano $(\mathrm{F}=1,64, \mathrm{p}=0,19)$, quer nos estudantes do $4^{\mathrm{o}}$ ano $(\mathrm{F}=0,26, \mathrm{p}=0,77)$.

A comparação do autoconceito global em função do nível sociocultural, considerados os resultados da ANOVA, não evidenciou quaisquer diferenças significativas, $(\mathrm{F}=0,24, \mathrm{p}=0,78)$. Também as ANOVA's efetuadas por ano de frequência permitem concluir que não existem diferenças nos níveis de autoconceito global de acordo com o nível sociocultural, quer nos estudantes 
do $1^{\circ}$ ano $(\mathrm{F}=0,13, \mathrm{p}=0,87)$, quer nos estudantes do $4^{\mathrm{o}}$ ano $(\mathrm{F}=0,23, \mathrm{p}=$ $0,79)$.

\section{Discussão e conclusões}

Da análise dos resultados obtidos, poderemos verificar que, no que diz respeito à relação entre o nível de autoconceito global e o ano de frequência no ensino superior ( $1^{\circ} \mathrm{e} 4^{\circ}$ anos), os resultados do nosso estudo não apontam para diferenças significativas.

Cairns, McWhirter, Duffy \& Barry (1990) afirmam que, apesar da estabilidade normativa, registra-se uma tendência para uma evolução favorável, que se traduz numa maior estabilidade estrutural e no incremento dos seus aspectos positivos, para os quais contribuem as vivências universitárias. Segundo esses autores, a adolescência tardia é um período do ciclo vital com modestos aumentos na avaliação de vários aspectos do autoconceito. A inexistência de diferenças significativas entre os dois grupos de estudantes, apontada pelos resultados do nosso estudo, não contribuem para a tese de uma subida gradual, apesar de pouco expressiva, do autoconceito ao longo do tempo. Não podemos, contudo, deixar de registrar que a diferença entre a média de idades dos estudantes iniciantes e finalistas é de apenas três anos.

No que toca às eventuais diferenças entre o nível de autoconceito global e o gênero, e apesar de muitos autores considerarem que a percepção global que o sujeito tem de si é mais favorável no sexo masculino (Marsh, 1989; Cairns, McWhirter, Duffy \& Barry, 1990; Fontaine, 1991a; Fontaine, 1991b; Block \& Robins, 1993; Marsh \& Byrne 1993; Bailey et al., 1987, citado por Dias \& Fontaine, 2001), o nosso estudo não registrou diferenças estatisticamente significativas entre sexos. Assim sendo, à semelhança de investigações como a de Dias e Fontaine (2001), concluímos que não se observam diferenças de gênero em relação aos níveis de autoconceito global, quer na amostra global, quer no início ou final da formação superior. Em contraposição, Alfeld-Liro e Sigelman (1998) concluíram não existirem diferenças de gênero antes da entrada na faculdade, mas verificaram que o autoconceito dos rapazes se torna mais positivo nessa transição. Não podemos deixar de atender ao fato de a nossa amostra não ser proporcional no que diz respeito à variável sexo, pelo que os resultados devem ser lidos com maior cautela.

A inexistência de diferenças significativas em termos de autoconceito global, quando tomamos em consideração o nível socioeconômico, parece associar-se à ideia de que o estatuto socioeconômico não tem impacto na forma como os sujeitos se concebem nessa fase da pós-adolescência, 
particularmente ao nível das vivências no ensino superior. É possível que a sua influência seja mais expressiva nas incursões da vida profissional e na idade adulta propriamente dita, na medida em que as expectativas sociais são, nessa fase, mais incisivas quanto a essas questôes. $\mathrm{O}$ sujeito que já se encontra integrado no mercado de trabalho poderá, ainda assim, interpretar o nível socioeconômico a que pertence em função da sua responsabilidade pessoal e posicionamento hierárquico social, sobretudo nos casos em que apresenta um padrão atribucional interno. Todavia, estudos como os de Wylie (citado por Marsh, Barnes, Cairns \& Tidman, 1984), não são conclusivos relativamente à influência do nível socioeconômico no autoconceito. Os nossos resultados podem associar-se ao fato de termos recorrido a uma medida global de autoconceito e não às diferentes dimensões que o compõem, à semelhança do que aconteceu no estudo de Valente (2002), que registrou diferenças de acordo com o nível socioeconômico.

Por último, relativamente às eventuais diferenças nos níveis de autoconceito global em função do nível sociocultural, também não foram encontradas diferenças estatisticamente significativas, isso apesar de Valente (2002) ter concluído que os pais com habilitações acadêmicas mais elevadas mostram-se mais capazes de apoiar os filhos na construção de um elevado autoconceito global, isso quando existe uma relação de vinculação segura entre pais e filhos. Assim, essa questão da vinculação, que não foi explorada no nosso estudo, pode querer sugerir que os níveis de autoconceito global se relacionam mais com a disponibilidade psicológica e afetiva dos progenitores do que, propriamente, com as suas habilitações literárias.

Constatando, com base nos nossos resultados, a inexistência de diferenças significativas entre os estudantes no início e no final da sua formação, é de admitir que os processos desenvolvimentais exijam um maior período de tempo para serem captados pelas metodologias transversais, pois, na verdade, a média de idades entre alunos no início e no final da formação superior é reduzida.

Quando pensamos nos estudantes que se preparam para ingressar o mercado de trabalho, identificamos um conjunto de preocupaçóes que condicionam o conceito de si mesmo. O modelo de ensino resulta, muitas vezes, numa desmotivação para a realização escolar, e a área de formação a que o jovem se dirige nem sempre recai nas suas preferências, mas depende das oscilações do mercado de trabalho, em termos de oferta e procura. Acresce ainda o fato de que são raros os cursos que garantem a segurança de que o jovem atinja de forma imediata a independência financeira na vida adulta. A saturação de algumas áreas de atividade e a ameaça recorrente do desemprego empurram 
muitos jovens para ocupações pouco diferenciadas, pouco desafiantes e pouco exigentes em termos de competências profissionais específicas que, em nenhum caso, favorecem o seu autoconceito, mas que podem constituir uma estratégia para lidar com "[...] l'ambiguïté des sentiments qui écartèlent les jeunes dans les moments charnières"3 (Rota, 1993, p. 60). Quando essas estratégias não são acionadas, o jovem vivencia então as angústias associadas à entrada na vida ativa. Elas se traduzem na procura do primeiro emprego, pro meio do envio do curriculum vitae (a maior parte das vezes, sem existir qualquer experiência profissional, que é comumente requerida pelas entidades empregadoras) e nas decepções das primeiras recusas. Por outro lado, a labilidade das profissóes, inerente à instabilidade laboral, faz com que, muitas vezes, o curso concluído não seja solicitado por saturação do mercado de trabalho. São também frequentes os fracassos profissionais nas primeiras experiências de trabalho dos jovens. A preparação teórica de muitos cursos superiores não se faz acompanhar de uma componente prática, por meio da qual as competências possam ser aplicadas ao vivo e em situação real, o que coloca sérios entraves ao desenvolvimento do jovem. Atualmente, em qualquer nível sociocultural, essa fase do ciclo de vida gera esse tipo de preocupações, psicologicamente muito mais ansiogênicas que nas geraçôes anteriores.

Outras são as ansiedades vivenciadas no momento da entrada para o ensino superior. Uma mudança radical prende-se com o afastamento de alguns dos pares que partilharam o desenvolvimento com o jovem ao longo do período da adolescência. Os percursos divergentes dos amigos que constituíam o grupo de pares fazem com que o jovem se encontre mais desorientado, pelo desaparecimento das suas referências afetivas, e coloca-o diante de outros desafios que passam pelo estabelecimento de novas redes relacionais, suficientemente compensadoras em relação a outras perdas. Esse processo de desvinculação e as inerentes inseguranças intensificam-se ainda mais quando o estudante é obrigado a sair de casa dos pais e a viver deslocado dos seus anteriores contextos de vida. Trata-se de desafios que, a par de outros especificamente relacionados com as vivências acadêmicas e com as exigências de adaptação a um novo ciclo de ensino, podem ser, no seu conjunto, elementos de perturbação no processo de transição para o ensino superior.

Globalmente, a convergência dos níveis de autoconceito global entre os alunos finalistas e os alunos no início da sua formação superior leva-nos a equacionar que, a par de uma tendência desenvolvimental para a estabilização do autoconceito, as vivências nessas fases de transição e as ansiedades com que,

"[...] a ambiguidade de sentimentos que preenchem os jovens em momentos cruciais." 
em ambos os casos, os jovens se confrontam acabam por amortecer eventuais mudanças mais visíveis que pudessem ter lugar. Sendo a adolescência um período de grande transformação em termos desenvolvimentais, acompanhada muitas vezes de sentimentos de falta de autenticidade e de dúvidas em relação ao self, a adaptação aos papéis desempenhados pelo jovem adulto proporciona uma maior tranquilidade e uma maior estabilização da imagem que os sujeitos constroem acerca de si próprios.

Por outro lado, a ausência de impacto das variáveis de natureza sociodemográfica no autoconceito global poderá pressupor que os processos desenvolvimentais relativos à construção do autoconceito dependem mais das vivências dos sujeitos e da sua história de vida, assim como da influência que os outros significativos têm nessa autopoiese. De fato, segundo o referencial teórico que privilegiamos, a forma como o sujeito interpreta as suas realidades e constrói as suas narrativas e significados pessoais atribuem-lhe um papel decisivo no seu próprio desenvolvimento e no delinear da sua trajetória desenvolvimental.

Dada a importância do autoconceito e autoestima, enquanto elementos centrais da personalidade [...] para a compreensão dos processos de adaptação aos diversos acontecimentos de vida, importa o desenvolvimento de programas de promoção de competências pessoais e sociais que contribuam para a promoção do autoconceito/autoestima (Custódio, Domingues, Vicente, Silva, Dias \& Coelho, 2010).

Salientamos assim a importância das repercussões que o autoconceito merece em termos de implicaçôes práticas.

Os resultados evidenciados pela nossa investigação devem ser interpretados de forma cautelosa, atendendo aos limites que caracterizam a abordagem de tipo transversal.4 De fato, "A abordagem longitudinal tornou-se indispensável para compreender as diferenças interindividuais no desenvolvimento, constituindo portanto uma ferramenta privilegiada" (Rossi, 1999). Para futuras investigações, sugerimos não só o recurso a esse tipo de metodologia como a outros métodos de recolha de dados, como as entrevistas, cujos dados analisados qualitativamente poderiam ser confrontados com os resultados apresentados neste estudo. Seria, igualmente, interessante contrapor os dados fornecidos por meio dos autorrelatos com os dados fornecidos por outros informadores privilegiados relativamente à forma como o sujeito se percepciona. Recomendamos, ainda, a realização de estudos

Apesar da sua fácil e de rápida aplicabilidade, enferma de algumas deficiências relacionadas com a impossibilidade da análise de relaçóes de desenvolvimento nos mesmos sujeitos ao longo da sua frequência no ensino superior. 
comparativos de jovens que frequentam o ensino superior com sujeitos que ainda não ingressaram nesse nível de ensino e com sujeitos que, após a sua formação superior, já se integraram no mundo laboral.

Outra limitação que identificamos relaciona-se com a circunscrição do estudo à análise do nível de autoconceito global, deixando de lado as múltiplas facetas ou dimensões do autoconceito. Com efeito, seria interessante verificar se os resultados encontrados para o autoconceito global se replicariam ou não em cada uma das suas facetas e, seria, igualmente interessante, conhecer como estas se correlacionam entre si.

Apesar de o nosso trabalho, pelos seus constrangimentos em termos de amostragem, não poder aceitar a sugestão de Valente (2002), quando afirma que valeria a pena que um outro estudo fizesse a replicação no universo nacional, apresenta-se como um contributo para a compreensão das questôes relativas ao autoconceito de jovens adultos, estudantes do ensino superior, no âmbito do contexto português. Tendo consciência da impossibilidade de realizar quaisquer generalizações a outras populações que não aquela que foi alvo de estudo, pretendemos enriquecer o espectro de contributos para a compreensão da temática em estudo.

\section{Referências}

Alfeld-Liro, C. \& Sigelman, C. (1998). Sex differences in self-concept and symptoms of depression during the transition to college. Journal of Youth and Adolescence, 27 (2), 219-244.

Azevedo, A. \& Faria, L. (2003). O autoconceito no ensino secundário português: estudo das qualidades psicométricas do SDQ III. Revista GalegoPortuguesa de Psicoloxía e Educación, 10 (8), 305-315.

Beyers, W. \& Goossens, L. (2003). Psychological separation and adjustment to university: moderating effects of gender, age, and perceived parenting style. Journal of Adolescent Research, 18 (4), 363-382.

Block, J. \& Robins, R. (1993). A longitudinal study of consistency and change in self-esteem from early adolescence to early adulthood. Child Development, 64, 909-923.

Byrne, B. (1996). Academic self-concept: its structure, measurement, and 
relation to academic achievement. In: B. A. Bracken (ed.), Handbook of selfconcept. Developmental, social and clinical considerations. (pp. 287-316). New York: John Wiley \& Sons, Inc.

Cairns, E., McWhirter, L., Duffy, U. \& Barry, R. (1990). The stability of self-concept in late adolescence: gender and situational effects. Personality and Individual Differences, 11, 937-944.

Crain, R. (1996). The influence of age, race, and gender on child and adolescent multidimensional self-concept. In: B. A. Bracken (ed.), Handbook of self-concept. Developmental, social and clinical considerations. (pp. 395-420). New York: John Wiley \& Sons, Inc.

Custódio, S., Domingues, C., Vicente, L., Silva, M., Dias, M. \& Coelho, S. (2010). Autoconceito/autoestima e vinculação nas relações de namoro em estudantes do ensino secundário. Actas do VII Simpósio Nacional de Investigação em Psicologia. Braga: Universidade do Minho.

Dias, M. \& Fontaine, A. (2001). Tarefas desenvolvimentais e bem-estar de jovens universitários. Lisboa: Fundação Calouste Gulbenkian.

Faria, L. (2003). A importância do autoconceito em contexto escolar. In: C. M. Lopes Pires, P. J. Costa, S. Brites \& S. Ferreira (orgs.). (pp. 87-98). Psicologia, sociedade \& bem-estar. Leiria: Editorial Diferença.

Faria, L. \& Azevedo, A. (2004). Manifestações diferenciais do autoconceito no fim do ensino secundário português. Paideia, 14 (29), 265-276.

Faria, L. \& Fontaine, A. (1990). Avaliação do conceito de si próprio de adolescentes: adaptação do SQD I de Marsh à população portuguesa. Cadernos de Consulta Psicológica, 6, 97-105.

Faria, L. \& Fontaine, A. (1992). Estudo de adaptação do Self Description Questionnaire III (SDQ III) a estudantes universitários portugueses. Psychologica, 8, 41-49.

Fontaine, A. (1991). Desenvolvimento do conceito de si próprio e a realização escolar na adolescência. Psychologica, 5, 13-31.

Fontaine, A. (1991b). O conceito de si próprio no ensino secundário: processo de desenvolvimento diferencial. Cadernos de Consulta Psicológica, 7, 33-54.

Gecas, V. \& Mortimer, J. (1987). Stability and change in the self-concept from 
adolescence to adulthood. London: Routledge \& Kegan Paul.

Harter, S. (1983). Developmental perspectives on the self-system. In: P. H. Mussen (ed.). Handbook of Child Psychology. (pp. 275-385). New York: Wiley.

Hattie, J. (1992). Self-concept. New Jersey: Erlbaum Associates.

Janeiro, I. \& Marques, J. (1999). Autoestima e atitudes de planeamento e de exploração da carreira em jovens do $9^{\circ}$ e $11^{\circ}$ anos. Revista Portuguesa de Psicologia, 34, 83-99.

Lima Santos, N., Rurato, P. \& Faria, L. (2000). Papel do autoconceito de competência cognitiva e da autoaprendizagem no contexto sociolaboral. Análise Psicológica, 2 (18), 203-219.

Marsh, H. W. (1989). Age and sex effects in multiple dimensions of selfconcept: preadolescence to early adulthood. Journal of Educational Psychology, $81,417-430$.

Marsh, H. W. (1994). Using the national longitudinal study of 1988 to evaluate theoretical models of self-concept: The Self-description Questionnaire. Journal of Educational Psychology, 86 (3), 439-456.

Marsh, H. W., Barnes, J., Cairns, L. \& Tidman, M. (1984). Self-Description Questionnaire: age and sex effects in the structure and level of self-concept for preadolescent children. Journal of Educational Psychology, 76 (5), 940-956.

Marsh, H. W. \& Byrne, B. (1993). Do we see ourselves as others infer: a comparison of self-other agreement on multiple dimensions of self-concept from two continents. Australian Journal of Psychology, 45, $49-58$.

Marsh, H. W. \& Hattie, J. (1996). Theoretical perspectives on the structure of self-concept. In: B. A. Bracken (ed.), Handbook of self-concept. Developmental, social and clinical considerations. (pp. 38-90). New York: John Wiley \& Sons, Inc.

Melo, R. (2005). Autoconceito e desenvolvimento de competências relacionais de ajuda: estudo com estudantes de enfermagem. Revista Referência, 1, 63-71.

Morales Vallejo, P. (2006). Medición de actitudes en psicología y educación. Madrid: Universidad Pontificia Comillas.

Rossi, J. (1999). Os métodos de investigação em psicologia. Lisboa: Instituto 


\section{Piaget.}

Rota, M. (1993). 18 à 25 ans. La postadolescence et ses problèmes. Paris: Dunot.

Santos, L. \& Almeida, L. (2001). Vivências acadêmicas e rendimento escolar: estudo com alunos universitários do $1^{\circ}$ ano. Análise Psicológica, 2 (19), 205217.

Seco, G. (1993). O autoconceito escolar em educadoras de infância: um estudo transversal. Revista Portuguesa de Pedagogia, 27 (1), 119-139.

Shavelson, R. J., \& Bolus, R. (1982). Self-concept: The interplay of theory and methods. Journal of Educational Psychology, 74, 3-17.

Simões, M. (2001). O interesse do autoconceito em educação. Lisboa: Edições Plátano.

Simões, M. \& Serra, A. (1987). A importância do autoconceito na aprendizagem escolar. Separata da Revista Portuguesa de Pedagogia, 21, 233252.

Stocker, J. \& Faria, L. (2009). Autoconceito e adaptação ao ensino superior: estudo diferencial com alunos da Universidade do Porto. Actas do X Congresso Internacional Galego-Português de Psicopedagogia. Braga: Universidade do Minho.

Valente, I. (2002). Autoconceito em estudantes de enfermagem. Coimbra: Quarteto.

Vaz Serra, A. (1986). A importância do autoconceito. Psiquiatria Clínica, 7, 57-66.

Veiga, F. \& Moura, H. (1993). Disrupção escolar e autoconceito dos jovens. Jornal de Psicologia, 11 (3), 15-21. 